\title{
SCIDoc

\section{Fournier's Gangrene in Upper Egypt, Case Series of 14 Patients}

\author{
Case Report
}

\section{Abulezz $T^{*}$}

Professor and Head of Plastic Surgery Department, Faculty of Medicine, Sohag University, Sohag, Egypt.

\section{Abstract}

Objectives: Fournier's gangrene is a rare but serious necrotizing infection of the skin and subcutaneous tissues affecting mainly the genital, perineal and perianal regions with poor outcome. Multidisciplinary approach ensures the best management with the mainstay of treatment is the repeated adequate surgical debridement. Broad spectrum antibiotics and hemodynamic support, if needed, are also crucial. Plastic surgery is concerned with reconstruction of the residual defect after control of the infection and stabilization of the patient's condition.

Methods: we present 14 patients with Fournier's gangrene in the period between July 2009 and August 2015. Those patients were evaluated and managed based on onset, severity of the problem, presence of predisposing factors, site and size of residual defects.

Results: Mean age of patients was 47.8 years, male to female ratio was 2.5:1, diabetes mellitus was the commonest predisposing factor, and the scrotum was most frequently involved site. No mortality has been recorded.

Conclusion: Fournier's gangrene is no longer a life threatening condition. It is best treated by early and repeated debridement under broad-spectrum antibiotic cover. Reconstruction markedly reduces financial and psychological stress of patients as well as hospital stay and accelerates early return to normal life.

Keywords: Fournier's Gangrene; Necrotizing Fasciitis; Perineal; Scrotum; Debridement.

Abbreviations: FG: Fournier's Gangrene; AIDS: Acquired Immunodeficiency Syndrome; FGSI: Fournier's Gangrene Severity Index; HBO: Hyperbaric Oxygen; VAC: Vacuum-Assisted Closure.

\section{Introduction}

Fournier's gangrene (FG) is rare rapidly progressive infective necrotizing fasciitis which involves mainly the genital, perineal and perianal regions but may extend to abdominal wall through fascial planes [1, 2]. It was considered a life threatening condition with poor prognosis particularly in immunosuppressed conditions including diabetes mellitus, malnutrition, acquired immunodeficiency syndrome (AIDS), autoimmune diseases, cancer, low socioeconomic status and chronic alcoholism [3]. Mortality rate of such emergency situation was reported to range from $4 \%$ to $75 \%$ of cases [4]. Increased mortality was noticed with advanced age and delayed diagnosis and treatment [5].

Fournier's gangrene was initially described by Baurienne in 1764 [6] but its pathology was described by Jean Alfred Fournier in 1883 who reported a fulminant gangrene of penis and scrotum in
5 young males [7].

It is more frequent in males with male to female ratio is 10:1 with peak incidence is between $5^{\text {th }}$ to $6^{\text {th }}$ decades of life [8]. Its incidence was estimated to be 1.6 per 100000 males with noticeably recent rise of incidence that may be attributed to increased mean age of population, increasing numbers of patients receiving immunosuppressive therapy and those with HIV infection [9].

Fournier's gangrene is a polymicrobial disease caused by mixture of gram positive, gram negative and anaerobic bacteria as well as fungi which act synergistically to initiate infection, invade tissues, cause microthrombosis and endarteritis obliterans with subsequent tissue hypoxia, ischemia, necrosis and eventually gangrene [5]. Also several cytotoxic agents are released, such as collagenases and streptokinases and contribute for progressive local tissue damage [1]. The source of infection is variable,

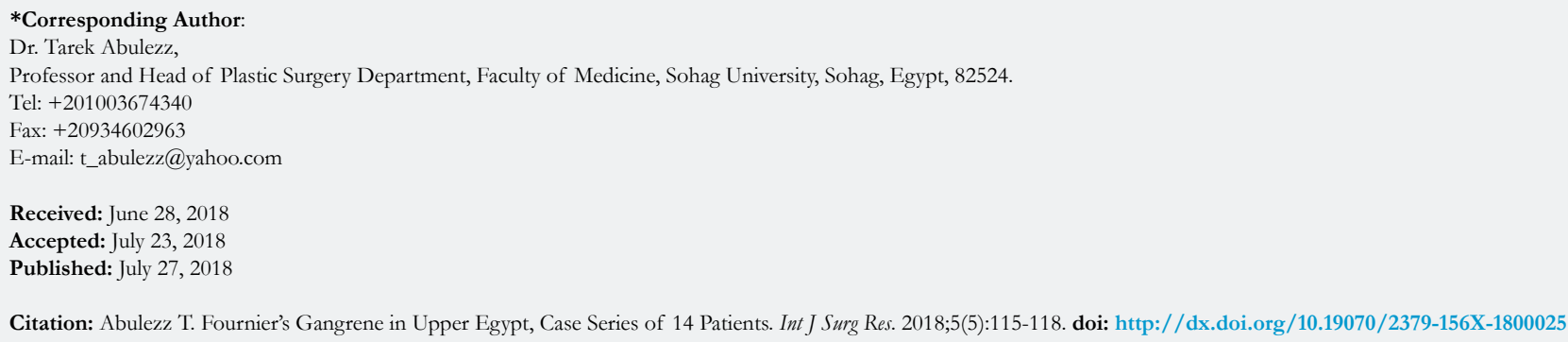

Copyright: Abulezz T $\mathbf{T}^{\circ}$ 2018. This is an open-access article distributed under the terms of the Creative Commons Attribution License, which permits unrestricted use, distribution and reproduction in any medium, provided the original author and source are credited. 
either anorectal, genitourinary or cutaneous, however, it can be identifiable in $95 \%$ of cases [10]. Escherichia coli is the most frequently isolated pathogen, but in more than $60 \%$ of cases the infection was polymicrobial [11].

Factors favoring development of Fournier's gangrene are numerous including poor perfusion, renal insufficiency, trauma, primary anorectal infections, liver cirrhosis, morbid obesity, spinal cord injuries and others [8]. Diabetes mellitus was the most frequently reported co-morbid condition associating with more aggressive course and poor prognosis however, most studies failed to prove its effect on the disease outcome [9]. The exact pathogenesis of Fournier's gangrene is still not completely understood [12].

The patient usually complains of local symptoms in genital and perineal regions such as pain, redness, discharge or crepitations. Sometimes general symptoms like fever and weakness may be present without local symptoms delaying diagnosis [5]. Therefore, the simplest complaints in genital, perineal or perianal regions particularly in aged patients should be considered and carefully evaluated [8]. Careful physical examination of perineal regions and genitalia in suspected cases is essential for early diagnosis. Imaging modalities are used to confirm diagnosis. X-ray can detect gas in tissues, Ultrasound confirms presence of diffuse edema and detects thickness of scrotal wall [6]. CT scan and MRI of are helpful for diagnosis and follow-up [5, 8]. Early diagnosis together with early aggressive debridement is the key for reducing mortality $[13,14]$.

Several scoring systems were described for assessment of aggressiveness. The most widely accepted is the Fournier's gangrene severity index (FGSI). It is simple objective tool which quantifies extent of metabolic aberrations and is good predictor of outcome $[15,16]$. Increased age $(>55$ years), total leucocytic count more than $15000 / \mathrm{mm}^{3}$, disease extension particularly to abdominal wall, presence of septic shock, need for postoperative mechanical ventilation, visual analog scale (VAS) $>7$ and FGSI $>$ 8 at admission, were significantly associated with higher mortality [17-19].

Fournier's gangrene is best managed via multidisciplinary approach conducted by general and plastic surgeons, urologist, microbiologist and nutritionist [20]. The principles of treatment are repeated aggressive surgical debridement, urinary and/or fecal diversion, intravenous broad spectrum antibiotics covering aerobic and anaerobic bacteria and long term hemodynamic support intensive care, when needed [21]. Hyperbaric oxygen (HBO) can be used as an adjuvant treatment with surgical debridement. It improves tissue oxygenation, potentiates patient immunity, enhances wound healing and lethal to anaerobic bacteria [22]. Vaccum-assisted closure (VAC) is another adjuvant therapy. It augments effect of $\mathrm{HBO}$ through removing the exudates, stimulating angiogenesis and reducing bacterial count [23]. Reconstructive procedures should be considered only after improvement of patient general condition and aim at defect coverage and maintaining penile function [24]. Defect coverage helps rapid and adequate improvement of patient condition. It can be achieved by either skin grafting which is easy procedure with cosmetically accepted results. Local flaps although cosmetically superior to skin graft, they are limited with prolonged morbidity [25]. Carvalho, et al., stated that precocious genital and perineal reconstruction in Fournier's gangrene has good outcome, reduces hospital stay and improves psychological condition of the patient [26].

\section{Patients and Methods}

This study included 14 patients presented with Fournier's gangrene in the period between July 2009 and August 2015. Four patients came to us in the acute stage with developing gangrene and the other 10 patients were referred to us from departments of general surgery and urology with post debridement skin defects for reconstruction. For the 4 patients with acute insult, surgical debridement was done, under coverage of broad-spectrum antibiotic in addition to metronidazol, followed by repeated dressings with povidone iodine and/or hydrogen peroxide. In one patient no reconstruction was required as the post debridement scrotal raw area healed gradually by secondary intention. For other patients various reconstructive procedures were performed depending on defect site and size. Split thickness skin grafting was done in 2 patients with raw area involving lower abdomen; for small perineal defects, refashioning closure was performed whereas larger defects needed transposition flaps from medial aspect of both thighs. Sizable scrotal defects with exposed testes were reconstructed by dissecting and mobilizing the residual scrotal skin flaps.

\section{Results}

Ten patients were males and 4 patients were females, with male to female ratio was 2.5:1. Age of patients ranged from 20 to 67 years with the mean age was 47.8 years old and $57 \%$ of patients were above the age of 50 years. The majority of patients were referred to us from other specialties (general surgery and urology) for reconstruction of residual defects whereas only 4 patients were presented with acute Fournier's gangrene of the scrotum. Six patients were diabetic $(42.9 \%$ of cases) and one patient was suffering from fecal fistula and was severely malnourished. Scrotum was the most frequently involved site; it was affected in all male patients of the study. The second commonest site was the perineum which was involved in 8 patients (57.1\% of cases). In 2 patients, there was extension to the abdominal wall. One patient needed temporary colostomy that was done by a general surgeon. The most commonly identified pathogen was E Coli and could be isolated from 11 cases out of the 14 cases (78.5\%). With follow up, all patients had good healing apart from the malnourished patient with fecal fistula who exhibited partial skin graft loss (less than $40 \%$ ) and needed further split-thickness skin grafting and referred to General Surgery for colostomy closure after complete skin graft healing.

\section{Case Presentation}

Three out of 14 patients were presented in this article; one patient was presented with acute scrotal gangrene whereas the other 2 patients were presenting with post debridement defects seeking reconstruction.

\section{Case 1}

Male patient, 24 years old, non diabetic, presented to our department with acute onset fever, scrotal swelling and pain, 
physical examination revealed scrotal oedema, tenderness and gangrene extending to perineum (Figure 1). Laboratory investigations revealed leucocytosis $\left(12700 / \mathrm{mm}^{3}\right)$, normal liver function tests and normal fasting blood glucose level. Urinary catheter was inserted. Surgical debridement was performed then repeated dressings with povidone iodine/hydrogen peroxide mixture combined with intravenous antibiotics. The wound become granulating and suitable for reconstruction by the $12^{\text {th }}$ day after admission. Reconstruction was done by mobilizing scrotal flaps for scrotal defect and primary closure of the perineal defect and patient was discharged after 3 days with good healing seen on follow up visits.

Figure 1. Male patient, 24 years with acute Fournier' gangrene of scrotum and perineum before debridement with urinary catheter inserted.

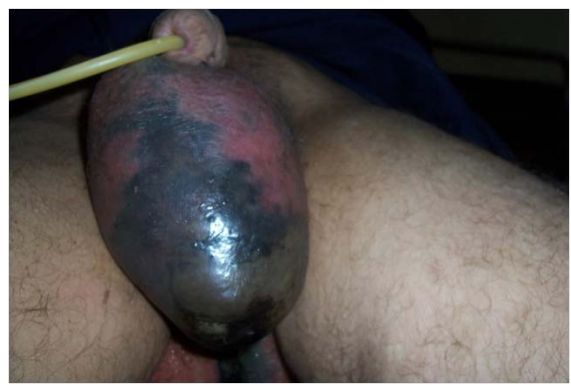

\section{Case 2}

Female patient, 58 years, diabetic, presented to our department with infected raw areas involving the right flank, infraumbilical region, right buttock, right labium major, back of right thigh and left trochanter (Figure 2) following debridement of Fournier's gangrene done in general surgery department. The patient had history of genital infection prior to onset of the gangrene. By examination, there was mild degree fever but the patient was generally well. A urinary catheter was inserted, culture and sensitivity of purulent exudates was done and antibiotic therapy was given according to the culture sensitivity with daily dressing. Closure of the perineal defects was done by local flaps and the rest of the raw area was reconstructed by split thickness skin graft. The patient was discharged after the second dressing of the grafted raw area. By follow up, healing was good and skin grafts were completely taken.

Figure 2. Female patient, 58 years with post Fournier's gangrene after debridement with clean raw areas of infraumbilical region, right buttock, back of right thigh, right labium major $A$. front view and $B$. back view.

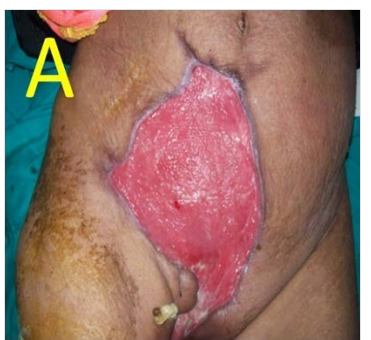

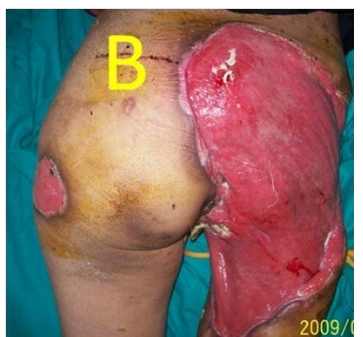

\section{Case 3}

Male patient, 55 years, diabetic, referred from urology department with history of Fournier's gangrene of scrotum 17 days ago. Debridement was done and the patient presented to our department with post debridement scrotal defect with exposed right testicle (Figure 3A). The patient was admitted and routine investigations were done. Refashioning closure of the scrotal defect was done (Figure 3B) and the patient had good healing and was discharged on the $4^{\text {th }}$ day postoperatively.

Figure 3. Male patient, 55 years with post Fournier's: A. defect of right side of the scrotum with exposed right testicle, B. 3 days postoperative after refashioning closure of the scrotal defect.

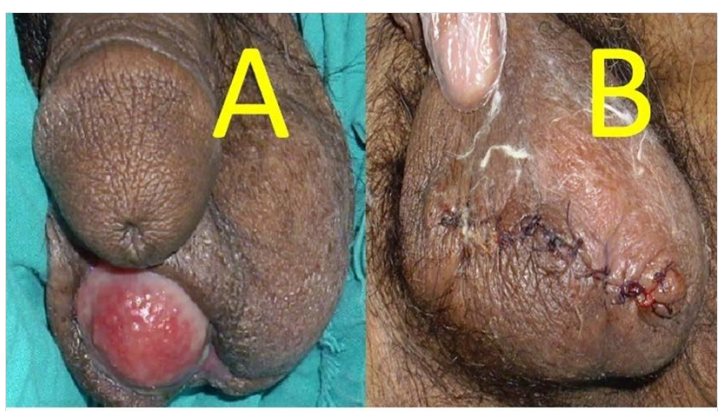

\section{Discussion}

Fournier's gangrene has been identified by many terms over the years including "streptococcus gangrene," "necrotising fasciitis," "periurethral phlegmon," "phagedena," and "synergistic necrotising cellulitis". It is a rare but may be fatal condition with low incidence worldwide [9]. In a review in 1992, Paty and coworkers found about 500 cases have been reported with FG since Fournier 1883 report, with a prevalence of 1 case in 7500 persons [10]. The largest case series were reported from Africa in 2014 [27]. However, we have treated 14 patients in 6 years. This relative high frequency may be attributed to bad sanitation, low socioeconomic status and poor nutrition. Moreover, the patient may be ashamed to seek medical advice early. Lastly, our hot climate may play a role by making the perineal region humid and more vulnerable to infection. Diabetes mellitus is the most commonly reported risk factor for the development of Fournier's gangrene [9], and in our series, we had 6 out of 14 patients having type 2 Diabetes Mellitus (43\%). The most common causative organism reported in literature was $E$ Coli [11] which was identified in $78.5 \%$ in our series.

Fournier's gangrene involves mainly genital, perineal and perianal regions but it may extend to abdominal wall $[1,2]$. In our series, the external genitalia were the primary site of involvement in 
most patients followed by the perineum.

Fournier's gangrene is much more common among males and very rare in females. In a review of 1726 cases the male: female ratio was 10:1 [28]. We found 6 females out of our 14 patients $(43 \%)$ of series were females. However this may be related to limited number of patients. The peak incidence of Fournier's gangrene is between $5^{\text {th }}$ and $6^{\text {th }}$ decades of life [8] and the mean presentation age of our series was 48 years.

Fournier's gangrene is potentially fatal condition with high mortality rate (up to 57\%) [4], in this series there was no mortality. This can be attributed to the fact that the majority of our patients were referred to us late for defects reconstruction after improvement of their general condition and passing the acute critical period of this insult.

Fournier's gangrene is a dilemma which is best managed by multidisciplinary team with the role of plastic surgeon is to reconstruct post debridement defects only after improvement of patient's condition [20, 24] and in this study, we co-operated with other colleagues in urology and general surgery departments to provide optimum management. Different reconstructive procedures were done depending on defect site and size with good outcome.

In this study we adopted the policy of early surgical reconstruction whenever needed and noticed that this considerably reduced hospital stay (mean hospital stay was 7 days) and significantly improves psychological condition of patients.

Adequate nutrition, improving sanitation, health education and early diagnosis are important for reducing incidence, minimizing mortality and improving outcome of Fournier's gangrene. Fournier's gangrene is no longer a life threatening condition. It is best treated by early and repeated debridement under broadspectrum antibiotic cover. Reconstruction markedly reduces financial and psychological stress of patients as well as hospital stay and accelerates early return to normal life.

\section{References}

[1]. Pastore AL, Palleschi G, Ripoli A, Silvestri L, Leto A, Autieri D, et al. A multistep approach to manage Fournier's gangrene in a patient with unknown type II diabetes: surgery, hyperbaric oxygen, and vacuum-assisted closure therapy: a case report. J Med Case Rep. 2013 Jan 3;7:1. doi: 10.1186/17521947-7-1. PubMed PMID: 23286211.

[2]. Corman JM, Moody JA, Aronson WJ. Fournier's gangrene in a modern surgical setting: improved survival with aggressive management. BJU Int. 1999 Jul;84(1):85-8. PubMed PMID: 10444130.

[3]. Sehmi S, Osaghae S. Type II diabetes mellitus: new presentation manifesting as Fournier's gangrene. JRSM Short Rep. 2011 Jun;2(6):51. doi: 10.1258/ shorts.2011.011055. PubMed PMID: 21731821.

[4]. Champion SE. A case of Fournier's gangrene. Urol Nurs. 2007 Aug;27(4):296-9. PubMed PMID: 17877098.

[5]. S Sokmen. Fournier gangreni. ANKEM Derg. 2012;26:331-6.

[6]. Smith GL, Bunker CB, Dinneen MD. Fournier's gangrene. Br J Urol. 1998 Mar;81(3):347-55. PubMed PMID: 9523650.

[7]. Fournier JA. Jean-Alfred Fournier 1832-1914. Gangrene foudroyante de la verge (overwhelming gangrene). Sem Med 1883. Dis Colon Rectum. 1988 Dec;31(12):984-8. PubMed PMID: 3063473.

[8]. Özşaker E, Yavuz M, Altınbaş Y, Şahin Köze B, Nurülke B. The care of a patient with Fournier's gangrene. Ulus Travma Acil Cerrahi Derg. 2015
Jan;21(1):71-4. doi: 10.5505/tjtes.2015.22735. PubMed PMID: 25779717.

[9]. Benjelloun EB, Souiki T, Yakla N, Ousadden A, Mazaz K, Louchi A, et al. Fournier's gangrene: our experience with 50 patients and analysis of factors affecting mortality. World J Emerg Surg. 2013 Apr 1;8(1):13. doi: 10.1186/1749-7922-8-13. PubMed PMID: 23547796.

[10]. Paty R, Smith AD. Gangrene and Fournier's gangrene. Urol Clin North Am. 1992 Feb;19(1):149-62. PubMed PMID: 1736475.

[11]. Morua AG, Lopez JA, Garcia JD, Montelongo RM, Guerra LS. Fournier's gangrene: our experience in 5 years, bibliographic review and assessment of the Fournier's gangrene severity index. Arch Esp Urol. 2009 Sep;62(7):53240. PubMed PMID: 19815967.

[12]. Fajdic J, Bukovic D, Hrgovic Z, Habek M, Gugic D, Jonas D, et al. Management of Fournier's gangrene--report of 7 cases and review of the literature. Eur J Med Res. 2007 Apr 26;12(4):169-72. PubMed PMID: 17509961.

[13]. Mehl AA, Nogueira Filho DC, Mantovani LM, Grippa MM, Berger R, Krauss D, et al. Management of Fournier's gangrene: experience of a university hospital of Curitiba. Rev Col Bras Cir. 2010 Dec;37(6):435-41. PubMed PMID: 21340259.

[14]. Unalp HR, Kamer E, Derici H, Atahan K, Balci U, Demirdoven C, et al. Fournier's gangrene: Evaluation of 68 patients and analysis of prognostic variables. J Postgrad Med. 2008 Apr-Jun;54(2):102-5. PubMed PMID: 18480525.

[15]. Roghmann F, von Bodman C, Löppenberg B, Hinkel A, Palisaar J, Noldus J. Is there a need for the Fournier's gangrene severity index? Comparison of scoring systems for outcome prediction in patients with Fournier's gangrene. BJU Int. 2012 Nov;110(9):1359-65. doi: 10.1111/j.1464-410X.2012.11082.x. PubMed PMID: 22494217.

[16]. Verma S, Sayana A, Kala S, Rai S. Evaluation of the utility of the Fournier's gangrene severity index in the management of Fournier's gangrene in North India: A multicentre retrospective study. J Cutan Aesthet Surg. 2012 Oct;5(4):273-6. doi: 10.4103/0974-2077.104916. PubMed PMID: 23378710.

[17]. Vyas HG, Kumar A, Bhandari V, Kumar N, Jain A, Kumar R. Prospective evaluation of risk factors for mortality in patients of Fournier's gangrene: A single center experience. Indian J Urol. 2013 Jul;29(3):161-5. doi: 10.4103/0970-1591.117255. PubMed PMID: 24082432.

[18]. Aridogan IA, Izol V, Abat D, Karsli O, Bayazit Y, Satar N. Epidemiological characteristics of Fournier's gangrene: A report of 71 patients. Urol Int. 2012;89(4):457-61. doi: 10.1159/000342407. PubMed PMID: 23076238

[19]. Sugihara T, Yasunaga H, Horiguchi H, Fujimura T, Ohe K, Matsuda S, et al. Impact of surgical intervention timing on the case fatality rate for Fournier's gangrene: an analysis of 379 cases. BJU Int. 2012 Dec;110(11 Pt C):E1096100. doi: 10.1111/j.1464-410X.2012.11291.x. PubMed PMID: 22726768

[20]. Brox-Jiménez A, Díaz-Gómez D, Parra-Membrives P, Martínez-Baena D, Márquez-Muñoz M, Lorente-Herce J, et al. A vacuum assisted closure system in complex wounds: a retrospective study. Cir Esp. 2010 May;87(5):312-7. doi: 10.1016/j.ciresp.2010.02.001. PubMed PMID: 20378103.

[21]. Altarac S, Katušin D, Crnica S, Papeš D, Rajković Z, Arslani N. Fournier's gangrene: etiology and outcome analysis of 41 patients. Urol Int. 2012;88(3):289-93. doi: 10.1159/000335507. PubMed PMID: 22433163.

[22]. Korhonen K, Hirn M, Niinikoski J. Hyperbaric oxygen in the treatment of Fournier's gangrene. Eur J Surg. 1998 Apr;164(4):251-5. PubMed PMID: 9641365.

[23]. Zagli G, Cianchi G, Degl'Innocenti S, Parodo J, Bonetti L, Prosperi P, et al Treatment of fournier's gangrene with combination of vacuum-assisted closure therapy, hyperbaric oxygen therapy, and protective colostomy. Case Rep Anesthesiol. 2011;2011:430983. doi: 10.1155/2011/430983. PubMed PMID: 22606389.

[24]. Parkash S, Gajendran V. Surgical reconstruction of the sequelae of penile and scrotal gangrene: a plea for simplicity. Br J Plast Surg. 1984 Jul;37(3):354-7. PubMed PMID: 6378298.

[25]. Black PC, Friedrich JB, Engrav LH, Wessells H. Meshed unexpanded splitthickness skin grafting for reconstruction of penile skin loss. J Urol. 2004 Sep;172(3):976-9. PubMed PMID: 15311016.

[26]. Carvalho JP, Hazan A, Cavalcanti AG, Favorito LA. Relation between the area affected by Fournier's gangrene and the type of reconstructive surgery used: a study with 80 patients. Int Braz J Urol. 2007 Jul-Aug;33(4):510-4. PubMed PMID: 17767755.

[27]. Ngugi P, Magoha G, Nyaga P. Fournier's gangrene in the HIV era. Afr Health Sci. 2014 Dec;14(4):1063-8. doi: 10.4314/ahs.v14i4.38. PubMed PMID: 25834518.

[28]. Eke N. Fournier's gangrene: a review of 1726 cases. Br J Surg. 2000 Jun;87(6):718-28. PubMed PMID: 10848848. 